\title{
Research-Practice Liaison in the Asian Scenario
}

\author{
Smita Khan \\ Assistant Professor, Department of Architecture \& Planning, \\ Visveswaraya National Institute of Technology, Nagpur. 440011. India \\ smitakhan@gmail.com
}

\begin{abstract}
This keynote paper examines the position of global south in world scenario and calls attention to the urgent need of a responsive architecture to counter the negativities and callousness that is seeping into the built developments due to rapid economic growth. It discusses the nature of a responsive self-practice \& observations of a recent research on learning environments, with focus on environ-behavior studies. It discusses the dire need of vital enrichment of policy and practice. The paper makes a case for E-B studies by exposing new challenges, nascent fields and the need to fine tune application of local and traditional learning enriched through people's experience and feedback in the Asian context.
\end{abstract}

Keywords: Global south; E-B studies; challenges; responsive practice \& research

eISSN: 2398-4295 @ 2016. The Authors. Published for AMER ABRA by e-International Publishing House, Ltd., UK.. This is an open access article under the CC BY-NC-ND license (http://creativecommons.org/licenses/by-ncnd/4.0/). Peer-review under responsibility of AMER (Association of Malaysian Environment-Behaviour Researchers), ABRA (Association of Behavioural Researchers on Asians) and CE-Bs (Centre for EnvironmentBehaviour Studies), Faculty of Architecture, Planning \& Surveying, Universiti Teknologi MARA, Malaysia.

https://doi.org/10.21834/ajbes.v1i2.30 


\subsection{Introduction}

The arena of Environment- Behaviour studies has risen to a commendable position in the global north, supported by more than half a century of research. This paper investigates the challenges and status of this field in the global south, analyses its contributing reasons and suggests a multi-pronged strategy to further E-B studies through policy, practice and pedagogy. It discusses the nature and contributions of a responsive architectural practice and the learnings of recent research on learning environs, to make its point.

\subsection{Challenges on ground}

Despite the phenomena of the shrinking world, ushered in by virtual technology (Friedman, 2006) burgeoning demographics coupled with volatile political set-ups continue to be the most significant characteristic of this region. Population burgeon most affects physical development. The built is the most visible manifestation of progress, yet the finer sensibilities of the art of building are overlooked. One such is the immense importance of the impact exerted by the built container upon those contained within its spatial confines. (La Gory \& Pipkin, 1981; Lawson, 2001). The vital importance of E-B studies is understated.

In a shrinking world scenario, this great divide notwithstanding between the Third World and the First World, trappings of the other world are manifest in isolated pockets in both: of prosperity and well-being in the midst of chaos and poverty and poverty and impoverishment in the midst of significant economic development. Frampton (2009) observes that whichever the case, the attitude towards the environment as a whole is getting increasingly barbaric. A great deal of inauthentic, acritical and insensitive building is occurring the world over. Happily, an incidental architecture of richness and subtlety may be found the world over simultaneously. In a situation of stark contrasts, this is a tiny semblance of similarity between the global north and south.

\subsection{Literature Review}

\subsection{Making a case for E-B studies in the Indian subcontinent}

The paper focuses on the Indian scenario citing critical influences on this arena of development.

i- $\quad$ Demographical composition: Ranking second in wide-wide comparison (figure 1), India possesses an intricately heterogeneous populace due to many sub-cultures. Democracy by default (Sen, 2005) its socialist commitments colours most societal endeavours. 


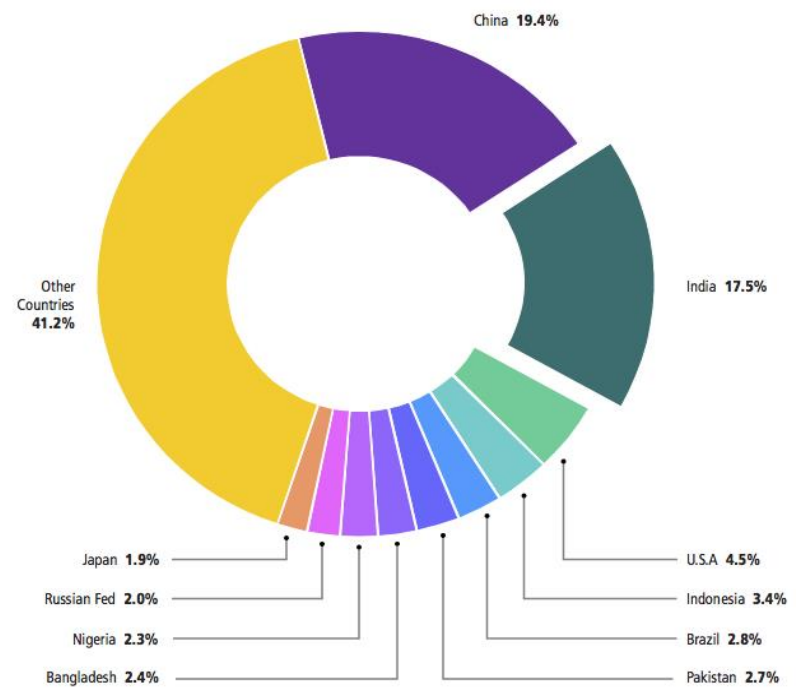

rıgure 1: Global demographıc comparıson

(Source: http://www.censusindia.gov.in)

ii- Status of E-B Studies in Architectural Education in India: The Council of Architecture (Handbook of COA, 2011) mandates registration of architects and regulates minimum standards of architectural education. Following data portrays the status of E-B field.

- Schools of Architecture: 338

- $\quad$ Students graduating each year: Approximately 3000

- $\quad$ Masters programs offered in: Approximately +47 schools

- $\quad$ Doctoral programs offered in: Approximately +12 schools

- $\quad$ Chartered architects in India: Approximately 60,000

- $\quad$ E-B Studies as a core or optional subject: Offered only in 5 architecture schools as undergrad elective

Miniscule stand-alone research and scattered development in this arena, cannot be ruled out. Although an accepted IT hub, e-documentation is under-developed, making networking on the study end difficult. Mainstream research eludes the E-B field. Despite half a century since its formal initiation, E-B arena remains unacknowledged in a nation holding approximately $1 / 6^{\text {th }}$ of the world's population! The critical need of a humane point of view in the developing urban scenario makes for an enormous challenge. 
iii- The current trends in built environment: Despite the vacillating global economic depression, India displays an upwardgrowth (http://www.tradingeconomics.com/india/gdpgrowth-annual) in the building industry.

Figure 2 previews the many ways in which the built is being manifest. Borrowing liberally from the global north, most architectural effort hinges upon the creation of a captivating visual expression. Such juxtapositions upon a land that is still steeped in the traditional are strange and alien. User responsiveness is not a priority. This makes a fit case for an urgent need for a studied approach to E-B studies.

Highlight on the main literatures reviewed:

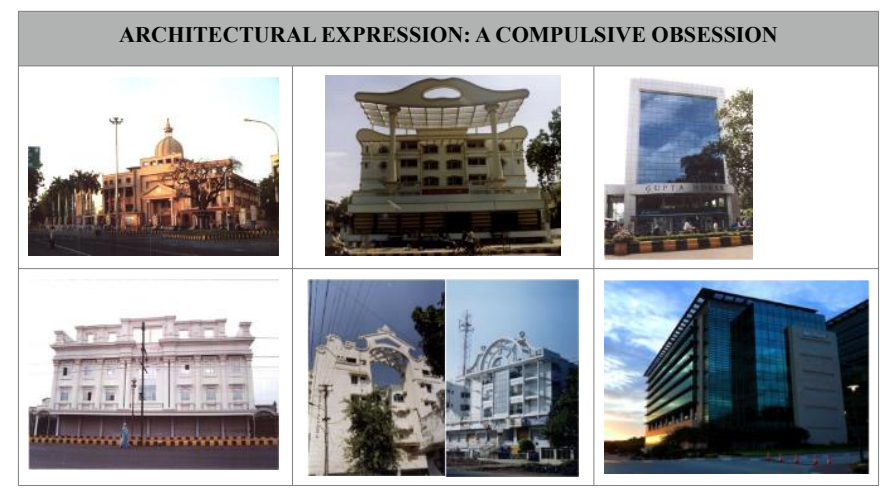

Figure 2: Alluring imagery of the contemporary built:

A strange juxtaposition

(Source: Author)

Even as these points make for a valid argument, Salingaros (2003) summarizes this situation in a succinct manner,

"Our civilization appears to be so complacent with its recent technological progress that it does not recognize threats to its very existence. We are distracted by technological toys and are not applying our scientific knowledge to keep our society in healthy working order. More traditional cultures are aware that something is dreadfully wrong, but they don't know how to react in a constructive manner."

The possibility of recognizing the wrong is jeopardized due to yet another dimension that marks our shrinking world. The global south communicates through ideas that belong to the global North influenced by the powerful media and the publications. The wisdom of local building traditions imbibed over ages, its actual application as a vigorous \& intelligent effort is shirked at large. In the process, something is going seriously wrong. The gap is 
large indeed! There is much aping and less reflection. As this famous quote by Jung points out,

A shoe that that fits a person pinches another, There is no recipe for living that suits all cases.

Despite pinching shoes, the capitalist bent of attitudes and images suits well the market forces in emerging economies. In this scramble for 'development' and 'nation building', most other dialogues take a back seat. The erosion of values is real. Ironically, in this process, one of the most vulnerable arenas, that is assigned a low rank in the list of priorities is that of environ- human relationship.

A much richer dialogue has to centre on this region for the betterment of the human environs. There is dire need for us, in Asia and Africa, to build a critical mass of academicians and theoreticians who can articulate a relevant debate much more strongly. We need reforms in our education systems to address issues and concerns that are pertinent in our contexts. We need public awareness and action on the ground to help inform new ways of looking at architecture and the built environment. (Mehrotra, 2012)

The architectural narratives have to focus on the following critical needs while keeping in view environ-behaviour relationship that is intrinsic in each arena.

1. A relevant architecture for the place,

2. An appropriate climatic response in these times of energy crisis,

3. Issues of technology \& suitable materials within a cost effective framework,

4. Issues of crafting buildings that are hand-made \& thus labour intensive, keeping in view our intense human resource,

5. Addressing questions of sustainability. In this arena also, western paradigms are relied upon which are not applicable in our contexts.

6. Issues of education for the population as a whole, for all the inhabitants, are stakeholders of the built environ.

7. Relevant research and publications addressing issues on the ground \& their dissemination.

\subsection{Methodology and Discussion}

This paper refers to the author's practice and research that has been endeavouring to create a responsive built as a challenge to the situation portrayed above.

\subsection{Learning from a responsive practice}

The practice attempts to devise and implement an architectural language based on the rich traditions of the past \& assimilating Indian principles encompassing freedom \& responsibility, creativity \& common sense, continuity \& growth, problem solving with creativity, aesthetic aspirations and construction technology, crafts \& craftsmanship, within a contemporary framework (Khan, 2012). To create architecture, for the people, which 
Khan, S. / Asian Journal of Behavioural Studies, AjBeS, 1(2), July/August 2016 (p.23-35)

belongs to the land and its ethos is the first step towards humanizing it for human wellbeing. 'The ten commandments' which are essential principles of the practice are illustrated in Figure 3.

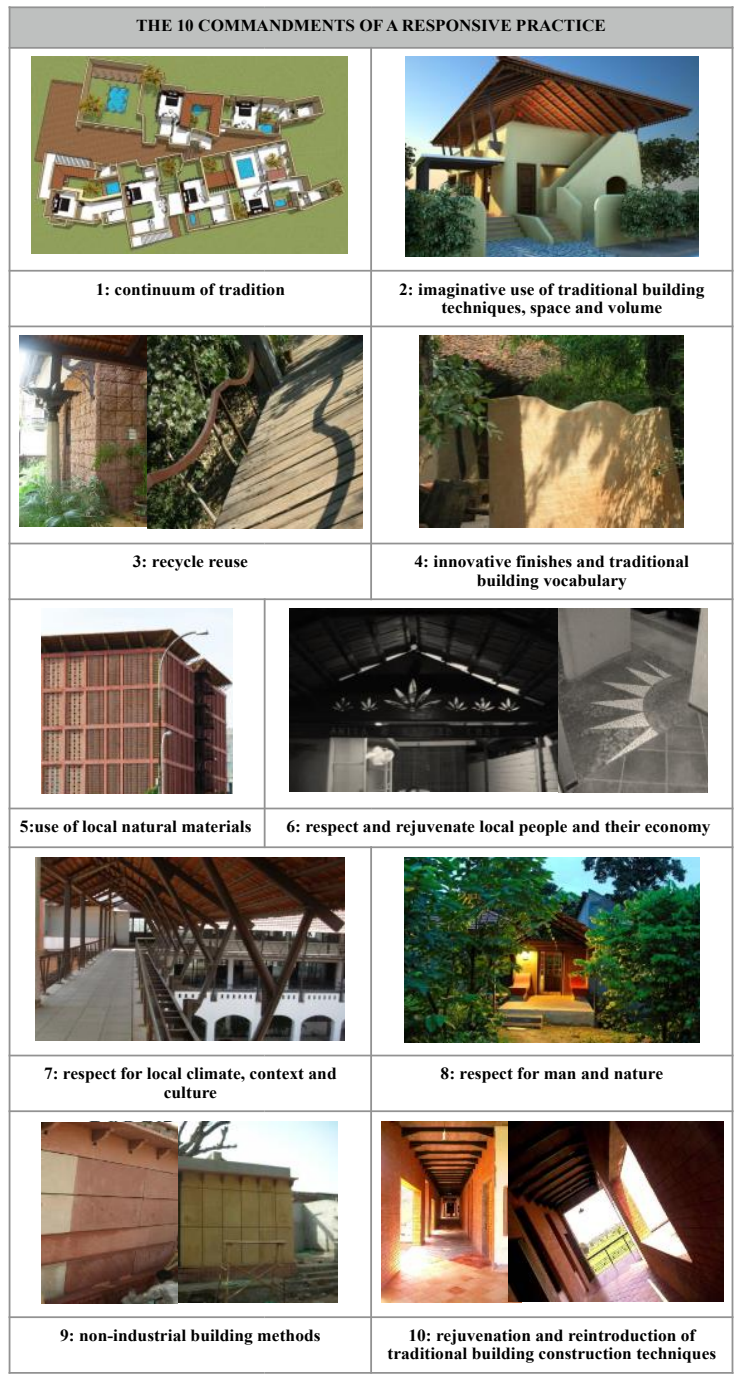

Figure 3: Ten Commandments of a Responsive Practice (Source: Author) 
These have helped conceive an architecture that is contextually relevant. Its quiet sense of aesthetics seeks to achieve what stark modernism has wiped out. Such architecture has been well received, and wholehearted accepted by the clients and many students have taken it up for case studies.

\subsection{Need for synergizing practice and research}

Current architectural practice banks upon trial and error methods on ground. User response and feedback in use and experience of this kind of architecture would aid in revising and reworking this contemporarily vernacular built.

In the absence of a strong practice-research paradigm, some pre-emptive practitioners have independent cells for back up research and dissemination of knowledge. Doshi's Vastushilp Foundation (n.d), Baker's (n.d) experimentations in appropriate, affordable building techniques and Kamil Khan Mumtaz's Anjuman Mimaran (n.d) an institution to disseminate traditional building skills amongst skilled craftsmen are a prominent few examples in the Indian sub-continent. The Central Building Research Institute (CBRI, n.d) at Roorkee, India is a government-funded organization. Building codes find such inputs of great value. The human element as a focus is still an unattended area.

Post Occupancy Evaluation, an established concept in the West has yet to arrive in India. While technical- functional aspects find reflection in policies and building codes, meta-physical -behavioural gets lip service. Policies bypass it and practice leaves it to intuition. The need of the hour is a strong collaboration of the academia and research with the practice, so each shall share and grow symbiotically.

Educational orientation has a vital contribution. Architectural Pedagogy in the Indian sub-continent focuses primarily on form-based design. Very few schools allow a researchbased thesis inquiry. Few architects articulate on the issues and concerns that effect their practice. Lateral research pre-occupations are missing from basic level itself. Many practitioners expressed difficulty in comprehending the crisp technical lingual expression of research. The academia has to take a step forward, and pen research works in a userfriendly format for greater dissemination in a diversely positioned architectural fraternity to be of help to the busy practitioner.

Education of the society in environmental design matters should be given highest priority to build up an aware, sensitive and responsible client base. Frampton (2009) emphasizes this as the first point of his seven-point manifesto for the millennium. Nowhere more than the Indian sub continent is this closer to the truth. Aware pressure groups and widespread intellectual debate is the need of the hour. Problems of application and execution are far more complex, and the point where most endeavours face disaster.

\subsection{Learning from research: A case for policy and practice}

Learning environs have great stakes in early sensitization, for these are the spaces within which behaviour and character are moulded. (Day, 2007; Hill, P. et al, 1990) A recent research enquiry by the author focusing on the urban secondary schools finds deep 
relevance in this discussion. These cater to the upwardly mobile middle class that is educated, urbane and represents -approximately $25 \%$ of the demography. Their number is small, yet their predominant urban existence makes them most prone to the urban malaises.

The numbers of urban private schools have had an exponential rise in the recent times. These are schools designed by architects and support a basic education that is regulated by a policy framework and affiliation regulations that mandate adequate infrastructure.mAre these environs child-friendly? Are they affording the advantages of a benevolent built? How conducive are the built surrounds for a wholesome all round growth? What behavioural influences are acting upon them?

In a demographically unwieldy nation, the school as a typology exists in many layers. As a socialist nation, any action centered upon the underprivileged is lauded and finds support, by GO-s and by NGO-s. Most research thus centers on appropriate technology, virtual classrooms, safe drinking water and sanitation. (Technical note, Gol \& UNESCO, 2012; NSSI, 2012)

The research study looked for something beyond the need for sanitation and water. Ironically, this thought process is still alien to many in India. As a nation on the path of progress, it is essential to ingrain attitudes supportive of a humane development at the outset. It is also time to spread awareness of the impact of the built over human behaviour \& well-being. It is essential to spread awareness of its vital significance into the public domain so that people at large shall work towards and demand a user-sensitive response from the built they inhabit.

Currently most learning and applications in the arena of environ-behaviour studies are drawn from the rich database of the western world. Lack of indigenous research is deeply felt at every step. The author's active pre-occupation in the form of doctoral research brought to fore many issues of the learning environs of schools with regards to child friendliness. A rigorous POE conducted in more than a dozen urban schools, with students as major respondents, brought forth facts worth considering.

\subsection{Nature of education system: A societal attitude}

Indian education solicited international attention when President Obama, urged American students to learn from Bangalore and Beijing, to rise to the challenges the $21^{\text {st }}$-century offers. (Tol, 2010). While a few selected products of the system, are successful on a global rampage, a very contrary state of affairs exists on the ground. The larger than life emphasis on education makes it single tracked in its essential nature. Competition is a stark reality of a student's life in every sphere of engagement, making individuals who are fiercely competitive, tenacious and capable of endurance. On the flop side, there is insecurity, insensitivity and an over-riding lack of belonging that finds reflection in the society at large. Research across the globe endorses this link. (Eccles, J, et al.1993, Feldlaufer, H. et al.; 1988; Ames, C. (1992). Evans, G. W. (2006). 
It catapults the challenge of school learning environs, to be supportive, benign and capable of nurturing a sense of belonging \& emotional comfort in the young students; an atmosphere that shall be an antidote to the stress; a conducive teaching-learning environ where basic lessons can be imbibed in happiness, within the bounds of disciplinary \& functional integrity of the school.

\subsection{Result}

\subsection{Critical need for an appropriate environmental response}

A visual preview of some urban schools under study is shown in figure 4. Most schools are populous, with upwards of 2500-3000 students from class 1 to 12 . Along with studies, students learn to jostle for attention, for space and for making themselves heard.

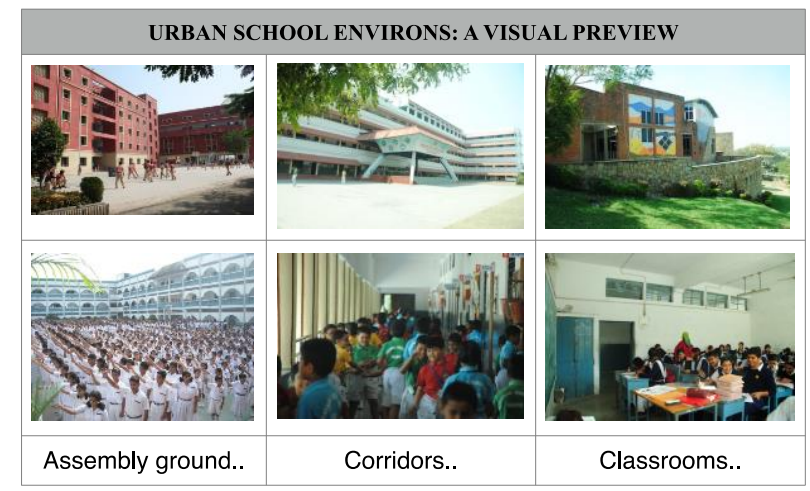

Figure 4: Urban Indian Schools: A Visual Preview

(Source: Author, 2013)

Table 5: Status of Child Centricity in Indian Urban Schools

\begin{tabular}{|l|l|c|c|c|}
\hline \multirow{2}{*}{$\#$} & CHILD CENTRIC PARAMETERS & \multicolumn{2}{|c|}{ RATING WISE CLASSIFICATION OF SCHOOLS } \\
\cline { 3 - 5 } & POOR LEVEL & $\begin{array}{c}\text { AVERAGE } \\
\text { LEVEL }\end{array}$ & $\begin{array}{c}\text { VERY GOOD } \\
\text { LEVEL }\end{array}$ \\
\hline 1 & Physical Comfort in using building & - & 11 & 3 \\
\hline 2 & Visual Expression & - & 7 & 7 \\
\hline 3 & Child Scale & 4 & 10 & - \\
\hline 4 & Spatial Cognizability and Legibility & - & 6 & 8 \\
\hline 5 & Hierarchy \& Defensible Space & 11 & 3 & - \\
\hline 6 & Interior Ambiance & 1 & 12 & 1 \\
\hline 7 & Physical Comfort in Interior Spaces & 7 & 5 & 2 \\
\hline 8 & Ergonomics & 2 & 10 & 2 \\
\hline 9 & Personal and Social Space & 10 & 4 & - \\
\hline 10 & Sense of Belonging & 1 & 11 & 2 \\
\hline 11 & Teaching- Learning Environs & 2 & 11 & 1 \\
\hline
\end{tabular}

(Source: Author, 2013) 
Post Occupancy Evaluation of 14 private urban schools holding consistent affiliation and academic record, brought forth vital observations. Eleven identified child-centric parameters vacillate between poor and average level. Those that have strong behavioural impacts score the least. It is indicative of the scope of research and inputs necessary. (Refer Table 5)

\subsection{Inputs are vital in 3 arenas:}

At the end of the students: There is a need to respond to the intrinsic requirements of student users, in a world created by adults. This is essential to prevent marginalization and to impart valuable lessons on the potentials of the spatial built environs to be supportive and caring. Subtle lessons unconsciously imbibed shape positive attitudes. This is a crucial need of our society at present.

At the end of the regulatory statutes: Policies and its regulations fall short of addressing the user, both at the educational framework end as well as at the end of the building regulations. This pinpoints the gap in governing school education and its built environs. Policy decisions are inadequate and incomplete without a studied approach to the vital issues of user-centric environmental design. Architects are a reticent community. Our abysmal representation on the planning boards is responsible for bureaucrats summarily framing policies with little knowledge of the critical implications of environs on users.

At the pedagogy and practice end: The traditional pedagogical approach that emphasizes on form, contemporary materials, and technology is shaping the architectural practice. Newer ways of looking at the built environs are yet understated. Environ-behaviour studies are not part of curricula in India. An awareness of the user and his problems and the potentials and limitations of existing settings to cater to them shall open a new way of perceiving the built environs. Continuing education is also a recent concept. E-B studies need initiation to sensitize practitioners towards critical needs of categorized users such as children, aged and elderly, women and differently challenged to mention a few.

Transformation of pedagogy, in this manner, shall usher in a more responsive \& responsible practice in the course of time.

\section{Conclusion}

This paper addressed the arenas the author has been involved actively in. It reveals the ground situation in most developing regions where the stakes are profoundly influenced by demography, economics, and politics.

The acceptance of an architectural language relevant to its context is making a miniscule presence. The craving for an iconic architectural presence results in borrowing liberally from the global north, in a conveniently skewed manner.

Nevertheless, a small section of the society has started perceiving humane attitudes that such architecture embodies. By respecting and recasting experiences close to the 
Indian way of life, the user is slowly coming into focus. Environ- behaviour studies are now imperative to make him the backbone of every built endeavour.

In conclusion, a re-iteration of a multi-pronged strategy is deemed fit.

- Environmental design education to be initiated at high school level.

- Architectural pedagogy based on POE and learning from ground realities

- Continuing education for practitioners

- $\quad$ Easy to refer publications

- $\quad$ Synergy between academics, research and practice with a hand-on approach

- $\quad$ Relevant inputs into policies; a more proactive role of the profession at large into policy frameworks

- Encouragement and support of indigenous research and compilation of a relevant, user-friendly database.

- Lastly, an emphasis on increasing global research collaborations across the spectrum of architectural and planning engagements.

The keynote does not put forth new concepts, but exposes new challenges; nascent fields and the need to fine-tune application of local \& traditional learning enriched through people's experience and feedbacks. While the intellectual supports are easy to build, it is execution on the ground that is the cause of failure of many a brilliant concept.

Inner peace and quiet, the mainstays of the esoteric East are at a discount. Callous, indifferent insensitive surrounds are aggravating the situation further. Nowhere than in the fast and haphazardly developing third world can this be experienced in full blast. Nowhere is the critical need of E-B studies pertinent than in the global south for betterment of a large chunk of global population through humane development.

\section{Acknowledgement}

Deep gratitude to the organizers of AicE-Bs 2013 for this keynote invite!

\section{References}

Ames, C. (1992). Classrooms: Goals, structures, and student motivation. Journal of educational psychology, 84(3), 261.

An Inclusive Approach for School Sanitation \& Hygiene Education: Strategy, Norms \& Designs. (2012).

Technical Note Series based upon the $7^{\text {th }}$ National Education Survey, UNICEF \& Government of India Collaboration.

Taimoor Khan. (n.d). Anjuman Mimaran. Retrived August 12, 2013 from http://www.lestariheritage.net/pakistan/index.html 
CBRI. (n.d.). Retrieved May 4, 2013 from http://www.cbri.res.in

Day, C. (2007). Environment \& Children: Passive lessons from the everyday environment. Elsevier Architectural Press, UK.

Eccles, J., Midgley, C., Wigfield, A., Buchanan, C., Reuman, D., Flanagan, C., \& Mac Iver, D. (1993). Development during Adolescence: The Impact of Stage-Environment fit on young Adolescents' Experiences in Schools and in Families. American psychologist, 48(2), 90.

Evans, G. W. (2006). Child Development and the Physical Environment. Annu. Rev. Psychol., 57, 423-451.

Feldlaufer, H., Midgley, C., \& Eccles, J.(1988). Student, Teacher and Observer perceptions of the Classroom Environment before and after the transition to Junior High School. The Journal of Early Adolescence, 8(2), 133156.

Frampton, K.(2009). Seven Points for the Millennium: An Untimely Manifesto. Keynote Speech. UIA 2009.

Friedman, T.(2006). The World is Flat: The Globalized World in the Twentieth Century. Penguin Books Ltd., UK.

Handbook of Professional Documents (2011). Council of Architecture. An Autonomous Statutory Body of Government of India under the Architects Act, 1972.

Hill, P., Foster, G., \& Gendler, T. (1990). High schools with character. Santa Monica, CA: Rand.

Jung, C. (n.d). Retrieved July 15, 2013 from https://www2.bc.edu/ bruyn/documents/CarlJungSayingspdf.pdf

Khan, H. (2012). Contemporary Vernacular: In Search of a Context Based Architecture. Paper presented at IAPS 2012, Glasgow @ http://www.iaps2012.org.uk/CaseStudies/CaseStudy_Khan.aspx

La Gory, M and Pipkin, J. (1981). Urban Social Space. Wadsworth Publishing Company. USA.

Lawson, B. (2001). The Language of Space. Architectural Press, UK.

Mehrotra, R. (2012). Guest Speech at the AZA2012, Cape Town.

Salingaros, N. (2002). INTBAU essay, vol.1 no. 3.

Sen, A. (2005). The Argumentative Indian: Writings on Indian Culture, History and Identity. Penguin Books Ltd., UK.

The National School Sanitation Initiative (NSSI). (2012). An Ministry of Human Resource and Govt. Of India Initiative. Retrieved from www.schoolsanitation.com

Times of India. (2010). Retrieved June 1, 2013 from http://articles.timesofindia.indiatimes.com/2010-1104/software-services/28226364_1_world-class-barack-obama

Vastushilpa, (n.d.). Retrieved January 3, 2013 from http://www.vastushilpa.org

Retrieved June 3, 2013 from http://www.censusindia.gov.in

http://www.tradingeconomics.com/india/gdp-growth-annual 
Khan, S. / Asian Journal of Behavioural Studies, AjBeS, 1(2), July/August 2016 (p.23-35)

Laurie Baker. Retrieved August 12, 2013 from http://www.lauriebakerbuildingcentre.com 